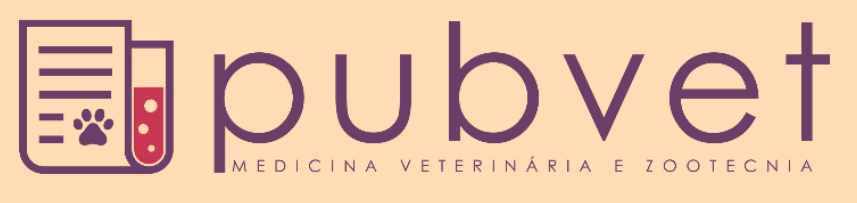

https://doi.org/10.31533/pubvet.v15n12a989.1-6

\title{
Toxoplasmose: Papel real dos felinos
}

\author{
Beatriz Suarez Alegrucci', Caio Yassuo Aguiar Ossada ${ }^{1}$, Gustavo Laranjeira Pierotti ${ }^{1 *}$, \\ Natália Rabello de Araújo ${ }^{1}$, Ed Wilson Santos ${ }^{2}$
}

${ }^{1}$ Discente da Faculdade de Medicina Veterinária da Universidade Anhembi Morumbi, São Paulo, São Paulo, Brasil. ${ }^{2}$ Professor da Faculdade de Medicina Veterinária da Universidade Anhembi Morumbi, São Paulo, São Paulo, Brasil. *Autor para correspondência, E-mail: araucciar2@gmail.com

\begin{abstract}
Resumo. Toxoplasmose é considerada uma doença sistêmica causada por um protozoário parasita intracelular obrigatório chamado Toxoplasma gondii, pertencente ao reino Protista, filo Apicomplexa e família Sarcocystidae. Possui um ciclo biológico heteroxênico, portanto, só pode ser completado quando possui dois ou mais hospedeiros, ocorrendo em duas fases diferentes: o ciclo extraintestinal assexuado e ciclo enteroepitelial sexuado, tendo como hospedeiro intermediário mamíferos e aves e hospedeiros definitivos os felídeos. É uma doença importante em relação à saúde pública, pois afeta mulheres grávidas, causando consequências deletérias a nível fetal. Já é sabido que os felídeos fazem parte da transmissão da Toxoplasmose, porém, diferente do que se acreditava antigamente, estes animais não apresentam um papel tão importante assim nesse quesito. $\mathrm{O}$ presente estudo decidiu avaliar o conhecimento de 472 pessoas a respeito disso, no qual foi concluído que a maioria dos entrevistados sabe que os felídeos não são os principais culpados na transmissão da doença. Entretanto, muitos responderam que a forma mais importante de prevenção é evitar contato com as fezes de gato ou substâncias que estejam contaminadas com essas fezes.
\end{abstract}

Palavras-chave: Ciclo extra intestinal, ciclo enteroepitelial, Toxoplasma gondii, toxoplasmose

\section{Toxoplasmosis: Real role of the felines}

Abstract. Toxoplasmosis is considered a systemic disease caused by an intracellular parasitic protozoan called Toxoplasma gondii, belonging to the Protista kingdom, phylum Apicomplexa and family Sarcocystidae. It has a heterogenic biological cycle; therefore, it can only be completed when it has two or more hosts. It occurs in two different phases: the asexual extraintestinal cycle and sexed enteroepithelial cycle, with mammals and birds and definitive hosts as felids as the intermediate host. It is an essential disease concerning public health, as it affects pregnant women, causing harmful consequences at the fetal level. It is already known that felids are part of the transmission of Toxoplasmosis; despite this, differently from what was believed in the past, these animals do not play such an important role in this regard. The present study decided to evaluate the knowledge of 472 people regarding this. It was concluded that most interviewees know that felines are not the main culprits in transmitting the disease. However, many responded that the most important form of prevention is to avoid contact with cat feces or substances contaminated with these feces.

Keywords: Extraintestinal cycle, enteroepithelial cycle, Toxoplasma gondii, toxoplasmosis

\section{Introdução}

Os gatos são os animais mais importantes na epidemiologia da toxoplasmose, pois são os únicos hospedeiros que podem excretar os oocistos (Dubey et al., 2020). O Toxoplasma gondii é um protozoário 
de ciclo de vida facultativamente heteroxeno e infecta todas as espécies de animais homeotérmicos, incluindo mamíferos, aves e o homem (Caldart et al., 2015; Dubey et al., 1970). Os gatos domésticos e outros felídeos são os únicos hospedeiros definitivos (Dubey, 2009). As aves e mamíferos servem como hospedeiros intermediários (Simpson et al., 2005). A enfermidade tem grande importância na saúde pública e acredita-se que cerca de 500 milhões de pessoas em todo mundo apresentam reação sorológica positiva para o parasito (Marobin et al., 2004).

A contaminação por toxoplasmose em felinos domésticos está associada à ingestão de carnes cruas ou tecidos (geralmente associado a predação), a falta de higienização em residências e no ambiente em que vive (Flegr et al., 2014). Para seu controle é preconizado a dedetização contra ratos, moscas, baratas, reduzindo a possibilidade de contaminação das populações naturais de felinos em espaços urbanos.

O consumo de água não filtrada deve ser evitado, pois também é um meio de transmissão para a doença (Dubey et al., 2004). Além disso, pode ocorrer a transmissão via placentária em diversos graus, na qual ocorre a passagem de taquizoítos. Outra forma de transmissão pode ser a partir da ingestão de oocistos em leite cru ou não pasteurizado (Ferreira et al., 2020).

Diante das diversas transmissões que a toxoplasmose pode ocorrer, há a possibilidade de estabelecer medidas de controle para que o animal ou ser humano evitem de adquirir a doença. Sabe-se que o indivíduo pode se infectar a partir da ingestão dos oocistos em solo, vegetais e frutas mal lavadas, água contaminada, ou disseminados por insetos, como, por exemplo, baratas e moscas (Robert-Gangneux \& Dardé, 2012); enquanto os felinos se infectam, principalmente, pelo carnivorismo ou pela ingestão de mamíferos infectados (Coiro et al., 2011). Os animais domésticos podem apresentar a doença a partir da ingestão de cistos em carnes cruas ou mal cozidas oferecidas pelos próprios tutores (AlvaradoEsquivel et al., 2012, 2014), assim, é importante não fornecer alimentos crus para os felinos, pois há uma chance de transmitir a doença.

Em ocasiões domésticas, pode-se incluir a higienização diária dos locais por onde os gatos defecam, removendo os dejetos adequadamente com o uso de luvas, álcool e desinfetante para evitar a possível transmissão, lembrando que gestantes não devem efetuar a limpeza da caixa de areia dos gatos. Além disso, é essencial lavar as mãos antes de consumir algum produto e, sempre que for ingerir algum alimento, é recomendável o cozimento adequado do mesmo, assim como a lavagem deve ser feita com água abundante para retirar os possíveis resíduos que ficam no alimento (Juránková et al., 2013; Mecca et al., 2011), pois produtos expostos aos insetos podem veicular o oocisto do Toxoplasma gondii (Spalding et al., 2005).

Em propriedades rurais, as medidas de prevenção são mais complicadas; porém, quando realizada, as rações dos animais devem ser cobertas para evitar o acesso de insetos (moscas), roedores e felinos (Hill et al., 2005). Produtos, como, por exemplo, o leite, deve ser ingerido apenas após sua devida pasteurização para que haja a fervura do mesmo e, assim, retirar os resíduos presentes (Cole et al., 2000; Frenkel, 1988).

Não há ainda uma vacina efetiva contra a toxoplasmose humana, apenas se encontra uma vacina comercial que é usada na Nova Zelândia e Grã-bretanha para a espécie ovina, denominada Toxovax ${ }^{\circledR}$, (Wastling et al., 1994) produzida a partir de taquizoítos vivos atenuados de uma cepa mutante S48 (Fialho et al., 2009), sendo utilizada nessa espécie para reduzir a formação de cistos teciduais.

\section{Material e métodos}

Pelo Google Forms foi realizada uma pesquisa respondida por pessoas de diversos lugares do país. Divulgada pelas redes sociais e aplicativos de mensagens, como Facebook, Twitter, Instagram e WhatsApp, a pesquisa abordou 472 pessoas, questionando-as sobre conhecimentos gerais a respeito da Toxoplasmose. Dos 472 indivíduos entrevistados, 163 possuem pós-graduação completa, 28 cursam pós-graduação, 158 tem ensino superior completo e 90 não finalizaram o ensino superior, enquanto os demais estão cursando ou ainda não completaram o Ensino Médio e o Ensino Fundamental. As perguntas de maior relevância realizadas foram: "Você sabe o que é uma zoonose?", "Quais as principais formas de transmissão da Toxoplasmose para os seres humanos?", "Você acha que grávidas podem ter contato com gatos?", "Você acha que os gatos são os culpados pela transmissão da doença aos humanos? e "Em relação a prevenção, o que pode ser feito?". 


\section{Resultados e discussão}

Das 472 pessoas entrevistadas, 379 delas responderam que o gato não é o principal culpado na transmissão da Toxoplasmose aos humanos, enquanto 93 pessoas acreditam que o gato seja o principal transmissor. A maioria das pessoas responderam que as gestantes podem manter contato com os felinos, desde que mantenham os devidos cuidados (Gráfico 1).

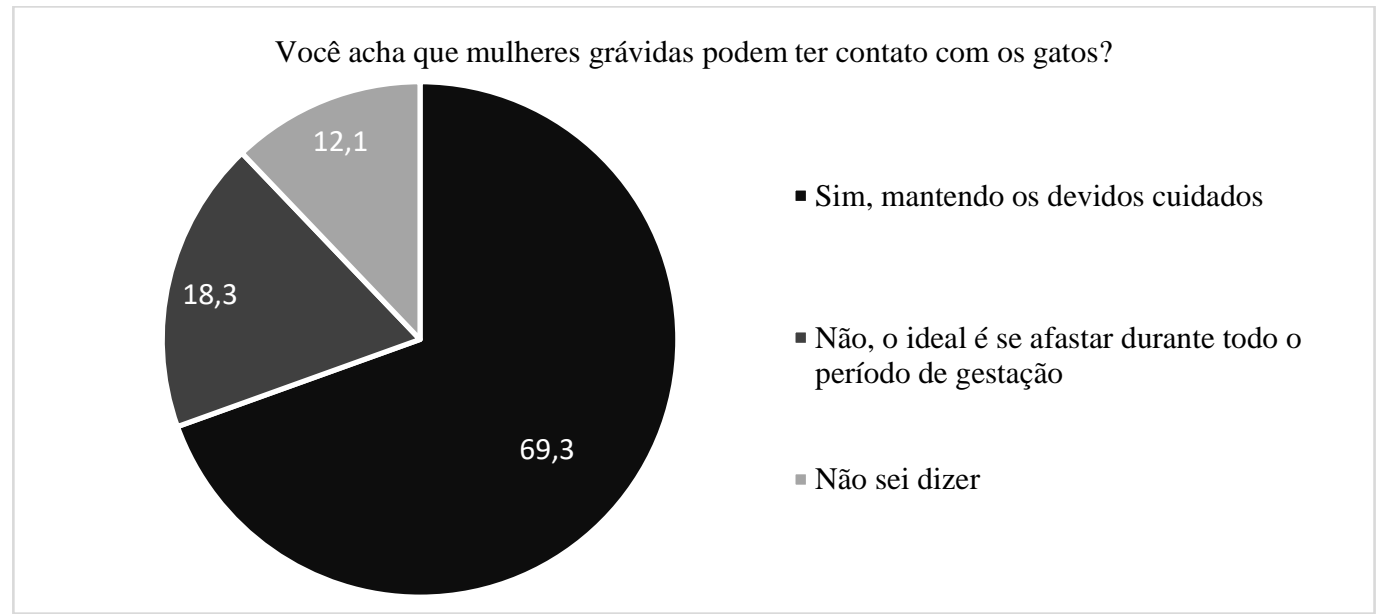

Gráfico 1. Você acha que mulheres grávidas podem ter contato com os gatos?

Embora a maior parte dos entrevistados tenha respondido que o gato não é o principal culpado na transmissão da doença aos humanos, nota-se que, ao observar o Gráfico 2, grande parte dos indivíduos respondeu que a principal forma de transmissão da doença é a partir do contato direto com as fezes do gato com Toxoplasmose. Apesar dos entrevistados terem demonstrado possuir bastante conhecimento a respeito da doença, houve divergências em relação aos métodos de prevenção e transmissão, como mostram as gráfico 2 e $\underline{3}$.

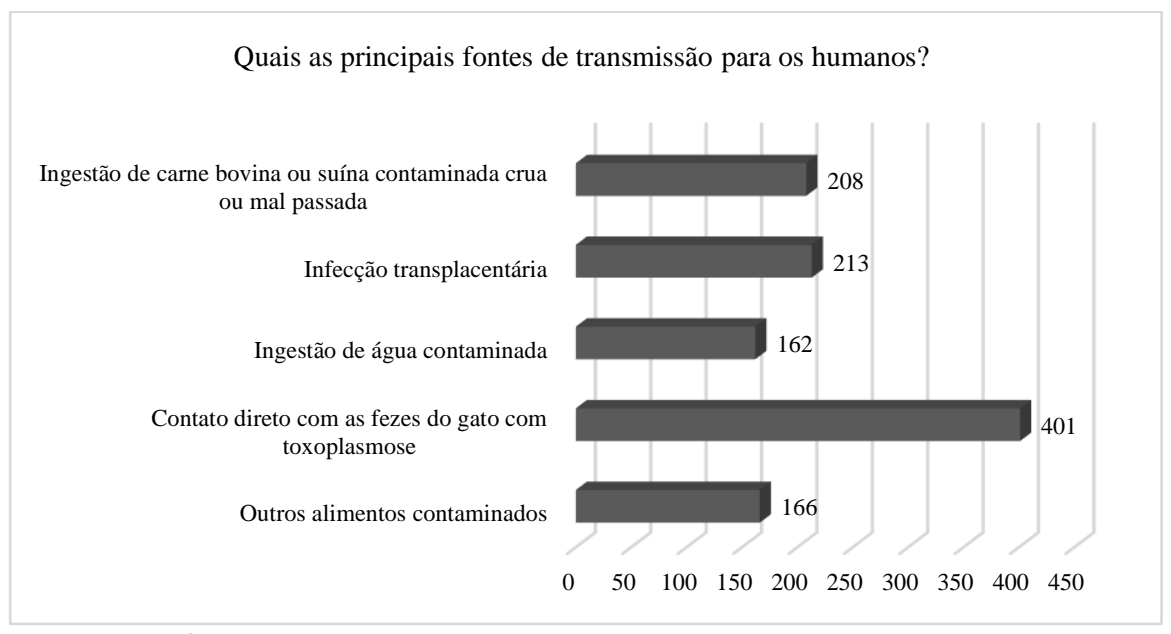

Gráfico 2. Quais as principais fontes de transmissão para os humanos?

Ao analisar a gráfico 3, observou-se que muitos pensam que a melhor forma de prevenção é evitar o contato com as fezes de gatos ou com substâncias que possam estar contaminadas com elas, seguida por lavar as mãos após manipular carne crua ou após contato com gatos ou outros animais e, em terceiro lugar, lavar com água abundante as frutas e verduras cruas.

Considerando que a principal forma de transmissão da Toxoplasmose é pelo consumo de carne crua ou mal passada (especialmente carne suína), o consumo de carne suína e a elevada disseminação e prevalência do $T$. gondii, associada ao fato de que os cistos não são detectáveis ao abate tornam este alimento, quando ingerido cru ou mal cozido em um importante via de transmissão da toxoplasmose ao homem (Millar et al., 2008). 
Percebe-se que grande parte dos entrevistados entendem que os felinos têm uma pequena parcela de culpa na transmissão da Toxoplasmose aos seres humanos, porém sabe-se que o indivíduo pode se infectar principalmente ingerindo oocistos em solo, vegetais e frutas mal lavadas, água contaminada, ou pelo consumo de cistos em tecidos de animais contaminados (Jericó et al., 2015), enquanto os felinos se infectam principalmente pela ingestão de carne contaminada (Cubas et al., 2014; Feldman, 1997; Larsson \& Lucas, 2016). Entretanto, os entrevistados não têm conhecimento a respeito da melhor forma de prevenção e nem da principal forma de transmissão.

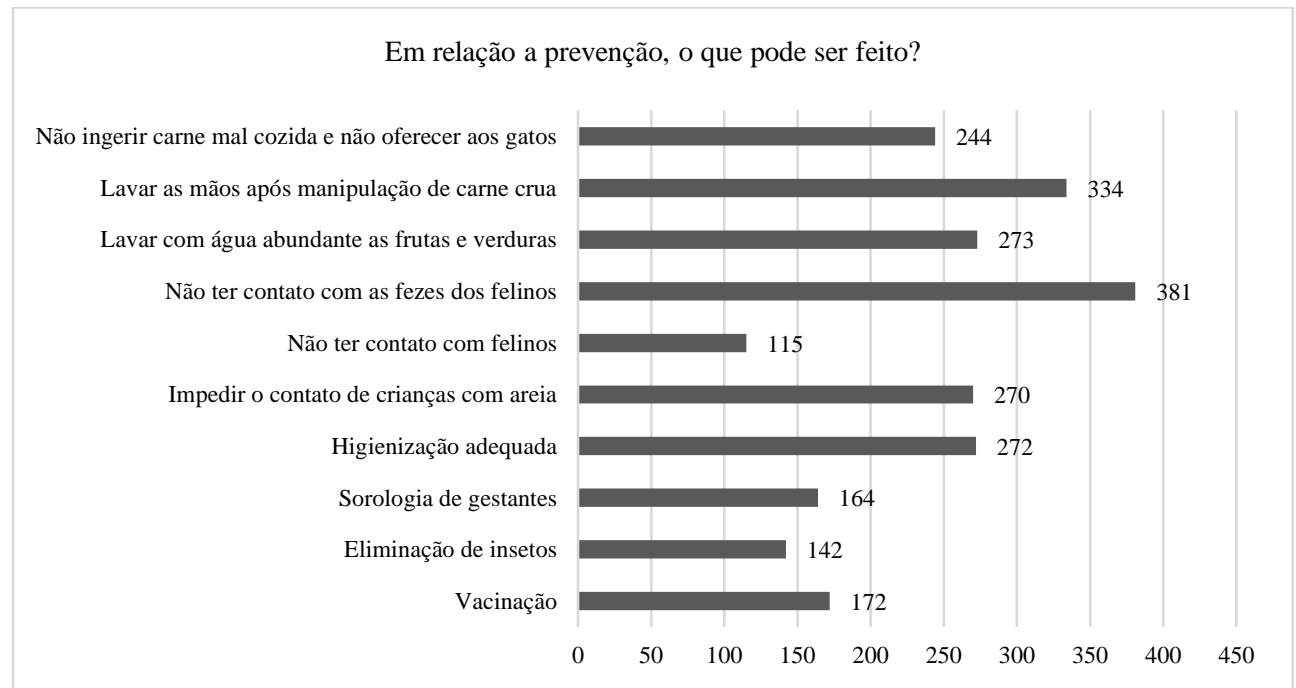

Gráfico 3. Em relação a prevenção, o que pode ser feito?

\section{Conclusão}

Nota-se que há uma importante contradição em relação à transmissão da doença e sua melhor forma de prevenção, pois apesar de a maioria dos entrevistados possuir conhecimento suficiente para saber que os felinos não são os principais culpados, muitos acreditam que a principal forma de transmissão é a partir do contato direto com as fezes dos felinos e, ainda, também acreditam que a melhor forma de prevenção é evitar contato com as fezes destes animais, o que torna as respostas contraditórias.

Isso levanta a possibilidade de que apesar dos entrevistados terem ciência de que os felinos possuem uma pequena parcela de culpa na transmissão da doença, talvez uma grande parte dos entrevistados ainda não saiba que a principal forma de transmissão é através da ingestão de carne crua ou mal-passada. Sendo assim, percebemos que realmente há uma falta de informação a respeito da Toxoplasmose, principalmente no que diz respeito à transmissão e prevenção.

Podemos concluir que, diante das informações recebidas e do conhecimento sobre a doença, muitos ainda acreditam que o felino é o principal transmissor da toxoplasmose devido às informações que as redes sociais trazem, no entanto, devemos dar uma maior ênfase aos alimentos que foram manipulados inadequadamente, tendo em vista que esse é a principal forma de transmissão da doença.

\section{Referências bibliográficas}

Alvarado-Esquivel, C., Hernández-Tinoco, J., Sánchez-Anguiano, L. F., Ramos-Nevárez, A., CerrilloSoto, S. M., Sáenz-Soto, L., \& Liesenfeld, O. (2014). High seroprevalence of Toxoplasma gondii infection in inmates: a case control study in Durango City, Mexico. European Journal of Microbiology and Immunology, 4(1), 76-82.

Alvarado-Esquivel, C., Torres-Castorena, A., Liesenfeld, O., Estrada-Martínez, S., \& Urbina-Álvarez, J. D. (2012). High seroprevalence of Toxoplasma gondii infection in a subset of Mexican patients with work accidents and low socioeconomic status. Parasites \& Vectors, 5(1), 13.

Caldart, E. T., Constantino, C., Pasquali, A. K. S., Benitez, A. N., Hamada, F. N., Dias, R. C. F., RoratoNascimento, A. M., Marana, E. R. M., Navarro, I. T., \& Mascarenhas, N. M. F. (2015). Zoonosis in dogs and cats attended by the Birth Control Project: Toxoplasma gondii, Leishmania spp. and 
Leptospira spp., serodiagnosis and epidemiology. Semina: Ciências Agrárias, 36(1), 253-265. https://doi.org/10.5433/1679-0359.2015v36n1p253.

Coiro, C. J., Langoni, H., Silva, R. C., \& Ullmann, L. S. (2011). Fatores de risco para leptospirose, leishmaniose, neosporose e toxoplasmose em cães domiciliados e peridomíciliados em Botucatu-SP. Veterinária e Zootecnia, 18(3), 393-407.

Cole, R. A., Lindsay, D. S., Howe, D. K., Roderick, C. L., Dubey, J. P., Thomas, N. J., \& Baeten, L. A. (2000). Biological and molecular characterizations of Toxoplasma gondii strains obtained from southern sea otters (Enhydra lutris nereis). Journal of Parasitology, 86(3), 526-530.

Cubas, Z. S., Silva, J. C. R., \& Dias, J. L. C. (2014). Tratado de animais selvagens-medicina veterinária. Editora Roca.

Dubey, J. P. (2009). History of the discovery of the life cycle of Toxoplasma gondii. International Journal for Parasitology, 39(8), 877-882.

Dubey, J. P., Cerqueira-Cézar, C. K., Murata, F. H. A., Kwok, O. C. H., Yang, Y. R., \& Su, C. (2020). All about toxoplasmosis in cats: the last decade. Veterinary Parasitology, 283, 109145. https://doi.org/10.1016/j.vetpar.2020.109145.

Dubey, J. P., Miller, N. L., \& Frenkel, J. K. (1970). The Toxoplasma gondii oocyst from cat feces. Journal of Experimental Medicine, 132(4), 636-662.

Dubey, J. P., Navarro, I. T., Sreekumar, C., Dahl, E., Freire, R. L., Kawabata, H. H., Vianna, M. C. B., Kwok, O. C. H., Shen, S. K., \& Thulliez, P. (2004). Toxoplasma gondii infections in cats from Paraná, Brazil: seroprevalence, tissue distribution, and biologic and genetic characterization of isolates. Journal of Parasitology, 90(4), 721-726.

Feldman, E. C. (1997). Tratado de medicina interna veterinária. In Moléstias do cão e do gato (Vol. 3).

Ferreira, J. V. F. V., Leite, R. B. C. H., Holanda, C. M. C. X., \& Barbosa, V. S. A. (2020). Soroprevalência para toxoplasmose em gestantes. Educação, Ciência e Saúde, 7(1), 101-116. https://doi.org/10.20438/ecs.v7i1.270.

Fialho, C. G., Teixeira, M. C., \& Araujo, F. A. P. (2009). Toxoplasmose animal no Brasil. Acta Scientiae Veterinariae, 37(1), 1-23.

Flegr, J., Prandota, J., Sovičková, M., \& Israili, Z. H. (2014). Toxoplasmosis-a global threat. Correlation of latent toxoplasmosis with specific disease burden in a set of 88 countries. PloS One, 9(3), e90203.

Frenkel, J. K. (1988). Pathophysiology of toxoplasmosis. Parasitology Today, 4(10), 273-278.

Hill, D. E., Chirukandoth, S., \& Dubey, J. P. (2005). Biology and epidemiology of Toxoplasma gondii in man and animals. Animal Health Research Reviews, 6(1), 41-61.

Jericó, M. M., Kogika, M. M., \& Andrade Neto, J. P. (2015). Tratado de medicina interna de cães e gatos. Guanabara Koogan.

Juránková, J., Opsteegh, M., Neumayerová, H., Kovařčík, K., Frencová, A., Baláž, V., Volf, J., \& Koudela, B. (2013). Quantification of Toxoplasma gondii in tissue samples of experimentally infected goats by magnetic capture and real-time PCR. Veterinary Parasitology, 193(1-3), 95-99. https://doi.org/http://dx.doi.org/10.1016/j.vetpar.2012.11.016

Larsson, C. E., \& Lucas, R. (2016). Tratado de medicina externa: dermatologia veterinária. Interbook.

Marobin, L., Flôres, M. L., Rizzatti, B. B., Segabinazi, S. D., Lagaggio, V. R. A., Grigulo, M., \& Scalco, M. A. (2004). Prevalência de anticorpos para Toxoplasma gondii em emas (Rhea americana) em diferentes criatórios do Estado do Rio Grande do Sul. Brazilian Journal of Veterinary Research and Animal Science, 41, 5-9.

Mecca, J. N., Meireles, L. R., \& de Andrade Jr, H. F. (2011). Quality control of Toxoplasma gondii in meat packages: Standardization of an ELISA test and its use for detection in rabbit meat cuts. Meat Science, 88(3), 584-589. https://doi.org/http://dx.doi.org/10.1016/j.meatsci.2011.01.016

Millar, P. R., Daguer, H., Vicente, R. T., Costa, T. da, Sobreiro, L. G., \& Amendoeira, M. R. R. (2008). Toxoplasma gondii: estudo soro-epidemiológico de suínos da região Sudoeste do Estado do Paraná. Pesquisa Veterinária Brasileira, 28, 15-18.

Robert-Gangneux, F., \& Dardé, M.-L. (2012). Epidemiology of and diagnostic strategies for toxoplasmosis. Clinical Microbiology Reviews, 25(2), 264-296.

Simpson, K. E., Devine, B. C., \& Gunn-Moore, D. (2005). Suspected toxoplasma-Associated 
myocarditis in a cat. Journal of Feline Medicine and Surgery, 7(3), 203-208. https://doi.org/10.1016/j.jfms.2004.08.004.

Spalding, S. M., Amendoeira, M. R. R., Klein, C. H., \& Ribeiro, L. C. (2005). Serological screening and toxoplasmosis exposure factors among pregnant women in South of Brazil. Revista Da Sociedade Brasileira de Medicina Tropical, 38(2), 173-177.

Wastling, J. M., Harkins, D., \& Buxton, D. (1994). Western blot analysis of the IgG response of sheep vaccinated with S48 Toxoplasma gondii (Toxovax). Research in Veterinary Science, 57(3), 384-386.

Histórico do artigo:

Recebido: 7 de agosto de 2021

Aprovado: 7 de setembro de 2021

Disponível on-line: 19 de novembrode 2021

Licenciamento: Este artigo é publicado na modalidade Acesso Aberto sob a licença Creative Commons Atribuição 4.0 (CC-BY 4.0), a qual permite uso irrestrito, distribuição, reprodução em qualquer meio, desde que o autor e a fonte sejam devidamente creditados. 